University at Buffalo School of Law

Digital Commons @ University at Buffalo School of Law

\title{
Conservation without Nature: the Trouble with In Situ Versus Ex Situ Conservation
}

Irus Braverman

University at Buffalo School of Law

Follow this and additional works at: https://digitalcommons.law.buffalo.edu/journal_articles

Part of the Law Commons, and the Natural Resources and Conservation Commons

\section{Recommended Citation}

Irus Braverman, Conservation without Nature: the Trouble with In Situ Versus Ex Situ Conservation, 51 Geoforum 47 (2014).

Available at: https://digitalcommons.law.buffalo.edu/journal_articles/333

(C) 2013 Elsevier Ltd. This manuscript version is made available under the CC-BY-NC-ND 4.0 license http://creativecommons.org/licenses/by-nc-nd/4.0/

\section{c) (i) () $९$}

This work is licensed under a Creative Commons Attribution-NonCommercial-NoDerivatives 4.0 International License.

This Article is brought to you for free and open access by the Faculty Scholarship at Digital Commons @ University at Buffalo School of Law. It has been accepted for inclusion in Journal Articles by an authorized administrator of Digital Commons @ University at Buffalo School of Law. For more information, please contact lawscholar@buffalo.edu. 


\title{
Conservation without Nature \\ The Trouble with In Situ versus Ex Situ Conservation
}

\author{
Dr. Irus Braverman
}

What is it that we want? Much of what conservation biology must do is confused by notions of animal "wildness," and "freedom," and even by the belief of a few that when a species' historical home is altered, that species is no longer worthy of interest.

--William Conway, in Ballou et al. Population Management for Survival or Recovery, xix

Strange as it may sound, the idea of nature is getting in the way of properly ecological forms of culture, philosophy, politics, and art.

--Timothy Morton, Ecology without Nature, 1

Although understudied by historians of science and mostly unheard of by the general public, the in/ex situ terminology has shaped - and still very much shapes - the development of the nature conservation movement and its various alliances and goals. One of the most important legal texts of the conservation movement to date, the 2002 Convention on Biological Diversity (CBD), defines "In-situ conservation" as "the conservation of ecosystems and natural habitats and the maintenance and recovery of viable populations of species in their natural surroundings" (my emphasis). The term "Ex-situ conservation" is defined in the same text as "the conservation of components of biological diversity outside their natural habitats" (my emphasis). The International Union for the Conservation of Nature-one of the leading conservation organizations operating in the world today—adds that, "Ex situ collections include whole plant or animal collections, zoological parks and botanic gardens, wildlife research facilities, and germplasm collections of wild and domesticated taxa" (IUCN, 2002).

Latin for "in" and "out" of place ("situ"), the in situ/ex situ dichotomy in discourses of nature conservation often stands for the nature/captivity dichotomy. On one end, in situ is defined as on-site, conservation in a wild nature, while on the other end, ex situ is off-site, unnatural, or captive conservation. This definition embodies and naturalizes a few central 
assumptions: a) that such wild nature actually exists; b) that conservation in and of wild nature is always "in" place, while any other form of conservation is "out" of place; and c) that "in" is normatively preferable to "out." Put differently, to use in situ and ex situ in the context of nature conservation is to assume that such exclusive and neat spaces of "in" and "out" are the driving forces of conservation. Indeed, traditional conservation narratives rest upon this schism between in and ex situ space; without it, it seems difficult, if not impossible, for many to imagine what conservation could mean.

This article draws on more than fifty in-depth, semi-structured interviews with prominent conservationists from the zoo world and from wildlife organizations, identified through a snowball sampling method (Biernacki and Waldorf, 1981). I began this project by reinterviewing a few contacts that I had already established in my previous study of zoos (Braverman, 2012b), and gradually expanded the circle of interviewees through contacting conservationists whom these initial people knew and suggested would be relevant to my project. This sampling is not random; quite the contrary, most of my interviewees have one foot in the in situ world and the other foot in the ex situ world and have personally experienced some of the tensions and integrative processes they describe (for a more detailed depiction of this project's methodology see Braverman, 2014).

Quoting just a fraction of a much broader set of interviews, this article will expose, explore, and criticize the underlying assumptions of in situ versus ex situ conservation. I shall argue that the in situ/ex situ dichotomy in nature conservation should be challenged on similar grounds as the broader nature/culture, or nature/society, schism (Cronon, 1996; Hinchcliffe, 2007; Latour 1993). In particular, I will suggest that the prism offered by this terminology conveys a perception of wild nature that is anachronistic and romantic and that such views are 
incompatible with emerging critical understandings of naturecultures (Haraway, 2008) and multinatures (Latour, 2004, 2011; Lorimer, 2012), which question the simplistic division between wilderness and civilized culture by illuminating their interdependency and irrevocable fusion. In the current paradigm, in situ and ex situ—wild nature and captivity—are conjoined in a system of meanings and symbols. Without a wild, free, and pristine nature (in situ), captivity (and ex situ conservation) is meaningless; without the notion of captivity, nature as the very opposite of captivity cannot exist. I will claim that such a bifurcated and essentialist view of nature and captivity does not account for the many situs, or sites, of human-affected natures.

The idea that pristine nature will have to wither away in an ecological state of human society is not new (Morton, 2007: 1; Latour, 2004), nor is it a novel claim that our definition of nature will have to alter considerably to move away from notions of the pristine to include human natures (Castree, 2012; Cronon, 1996; Marris, 2011). Nonetheless, this idea has received renewed attention in the form of the debate over renaming the current geological epoch as the Anthropocene (Szerszynski, 2012; Latour, 2010; Lorimer, 2012). I would like to expand this idea into the realm of conservation biology—namely, to replace the discourse of nativity and indigineity with explorations of viability, vitality, and relationality that are self-reflective about the ethical and political issues at stake. In essence, I am proposing conservation without nature, in the traditional sense of this word at least (Braun, 2006; Lorimer, 2012).

Such explorations will not be new to the readers of this journal. Indeed, the site (or location) of conservation practices and philosophies is a topic that is geographic at its core. In particular, animal geographers have been very active in the area of human-wildlife studies. One of the main strands in this area has been to challenge consisting frameworks for approaching wildlife management. In "Living Roods and Brownfield Wildlife," for example, Jamie Lorimer 
employs a range of conceptual resources from relational geography, a tradition that is quite relevant for this project. "Broadly speaking," Lorimer writes, "relational geography understands identities such as 'nature' and 'society', or 'the urban' and 'the rural' as fluid, complex, and emergent from situated interactions and interconnections, rather than as fixed as immutable essences" (2008: 2046). My view of nature focuses, similarly, on preserving processes rather than idealized nature and wild bodies. In other words, it promotes an understanding of conservation that moves away from purity and toward hybridity, in the rich and variant ways already explored by hybrid geography (Whatmore, 2006). Such hybridity is not only of animal bodies, but also of regions and places. "No longer is conservation to be directed only at purified regions far removed from centres of civilisation" (Lorimer, 2008: 2056). Many of the spaces and bodies discussed in this article are, similarly, hybrid by nature. This hybridity paves the way for a shift in focus toward dynamic assemblages of human-nonhuman bodies and spaces. Such assemblages are similarly championed in the animal geography literature by Christopher Bear and Sally Eden in their work on marine fishery certification and the movements of "transient populations" across management borders (Bear and Eden, 2008), and in David Lulka's work on the attempts to curb the movement of bison bodies by Yellowstone National Park (Lulka, 2004). Like Lorimer, Whatmore, Lulka, and Bear and Eden, my work recognizes that there is a certain open-ended and anthropogenic nature to these human-nonhuman assemblages, which stands in contrast with the rigid categories of habitat/site/range in which conservationists traditionally conceive their world. Bruce Braun remarks similarly that landscapes should be understood as open-ended, rather than closed and natural, and that conservation must be directed at "the possibilities and consequences of a 'new earth' and 'new humanity' that is still to come" (Braun, 2006: 219). 
By problematizing the bifurcation of nature and human, wild and captive animals, and in situ and ex situ conservation, this article supports "an anthropology that is not just confined to the human but is concerned with the effects of our entanglements with other kinds of living selves" (Kohn, 2007: 4). Recent scholarship in "multispecies ethnography" (Kirksey and Helmreich, 2010) argues, similarly, for a fresh understanding of the material entanglements of humans with organisms that are not simply windows (or mirrors) into the symbolic concerns of humans but are rather themselves vital subjects who must be lived with, similar to "companion species" (Haraway, 2003) or "unloved others" (Rose and van Dooren, 2011).

This article will begin by exploring the meaning of the in situ/ex situ terminology in different disciplinary contexts. Next, it will explore the evolution of the in situ/ex situ dyad in nature conservation. This genealogical account will travel in between the worlds of dead and live matter, artificilia and naturalia, and between the seemingly disconnected institutions of museums and zoos. It will then move to focus on the uses of the terminology in the ex situ context of zoos, illustrating the various models that have evolved from the realization of the important connections, indeed the impossibility of the divide, between in situ and ex situ conservation.

\section{In Situ/Ex Situ: An Intra-Disciplinary Genealogy}

The terms in situ and ex situ are used in an overwhelming variety of disciplinary contexts. In art, in situ refers to a work made specifically for a host site, or one that takes into account the site in which it is installed or exhibited, also referred to as "site-specific" art. In computer science, an in situ operation is one that occurs without interrupting the normal state of a system. For example, an in situ upgrade would allow an operating system, firmware, or application to be upgraded while the system was still running. Under public international law, in situ refers to a 
government with effective control over a certain territory, in contrast to an exiled government. And in architecture in situ refers to construction that is carried out at a building site using raw materials, and is contrasted with prefabricated construction, whereby building components are made elsewhere and then transported to the building site for assembly (Wikipedia, "in situ").

Closest to nature conservation, in archeology in situ refers to an artifact that has not been newly moved from its original place of deposition, indicating that it is stationary or static. Such an artifact that is not discovered in situ is considered out of context and thus even meaningless (Abungu, interview). For example, in situ often refers to ancient sculptures that were carved in place, such as the Sphinx or Petra—which are distinguished from statues that were carved and moved, such as the Colossi of Memnon (Hamma, interview). In situ is defined as the place where an item was first excavated:

If talking from an archeological perspective, the country of origin is where the thing has been dug from [defines its status], not where it came from. Things move. Where you dug it from the ground is what is important, irrespective of where it was made. . . That discovery moment - that is the place of origin. So it could have come five kilometers away, could have come 100 kilometers away. But where you go and find it buried that is in situ and that is where it is. So if it is in Kenya and you discover it there and you dig it there, it belongs to that particular place ... that is where it belongs (Abungu, interview; my emphasis).

The various definitions of in situ-although quite different from one another-all assert importance to the "place of origin" and to the "country of origin" in particular. In what follows, I will trace the use of the in/ex situ terminology in the nature conservation discourse, pointing to its evolvement in plant conservation in the 1960 s and its more current adoption by conservationists in the 1980s and 1990s to replace the controversial and emotional language of captivity with the seemingly more remote scientific term equivalent in Latin: "ex situ" (Blumer, interview). 


\section{In Situ and Ex Situ in Nature Conservation}

The terms in situ and ex situ are foundational in the discourse of the nature conservation movement. Conservation biologists David and Lida Burney suggest, accordingly, that "Anyone who has taken a course in conservation biology, or even read a book on the subject, knows that there are fundamentally two kinds of conservation: in situ and ex situ" (2010). The ability to identify in situ is also intrinsically tied to the preferential treatment of plants and animals that have originated from the native environment, leading to a native-versus-alien species dichotomy in conservation, which many conservationists still consider to be a core guiding principle (Fleishman et al., 2011), although it is increasingly contested (Mark et al., 2011; Warren, 2009).

Initially, in/ex situ nature conservation was associated with the agricultural history of domestication and migration, and with the development of seedbanks in particular. The term in situ appears in many naturalist histories as a reference to a plant's original habitat, but its earliest use in the context of conservation appears to have been made during a 1967 Technical Conference on the Exploration, Utilization and Conservation of Plant Genetic Resources (Scarascia-Mugnozza and Perrino, 2002: 5). Seedbanks were originally developed to maintain the viability of seeds during travel, and thus the productivity of certain breeds. Collecting seeds and storing them for future use became the predominant method of ex situ conservation of plants. In the United States, seedbanks that existed before 1967 were mostly part of breeding programs (another method of ex situ conservation) managed by the Office of Foreign Seed and Plant Introduction initiated in 1898.

Until quite recently, most programs focusing on plant genetic diversity assumed that ex situ conservation of genebanks or botanical gardens is far preferable to in situ conservation methods, which often restrict human access to genetic resources. Along these lines, scholars have 
distinguished between "accumulation," which is thought of as characteristic of ex situ conservation and is based on the collection of genetic resources for human use, and "maintenance," characteristic of an in situ conservation that focuses on the survival of a habitat as it currently exists. While ex situ conservation has been a way to store germplasm, in situ conservation was usually not allowed for storage or removal of plants from their native habitats.

Because of the predominance of ex situ conservation in the history of agriculture, conservation was initially characterized as a utilitarian practice (Scarascia-Mugnozza and Perrino, 2002: 18). On the other end of conservation trends driven by "use" and configured within the ex situ conservation framework, in situ conservation was generally configured within the paradigm of wilderness management. The in situ practice was driven by what many critics suggest is an "Edenic narrative"- a desire to recreate or maintain an environment that recalls the biblical Eden (Slater, 1996: 115). This understanding of nature as Eden required a complete removal of human presence, the source of all pollution and destruction (Cronon, 1996; Smith, 1984).

Whereas initially adopted from other disciplines to indicate the importance of place for the utility of conservation management of plants, in the 1980s the in situ/ex situ terminology has gained more traction as a convenient replacement to the emotionally loaded terms "nature" and "captivity." This was (and still is) true especially in zoological circles, where the justification for holding animals in captivity has increasingly been contested by emerging animal rights and welfare discourses (Donahue and Trump, 2006). In place of the negative associations of the term "captivity," the term ex situ highlights the scientific dimension of such conservation initiatives. In the words of wildlife conservationist Evan Blumer, "the terminology began with this binary of 
captive versus wild, and then got broadened and softened by bringing the Latin into it with in situ and ex situ" (interview).

Legal texts similarly rely on and reinforce the understanding of in situ and ex situ conservation as the foundational spatial division for nature conservation policies. I have already mentioned the Convention on Biological Diversity's explicit bifurcation of conservation into two separate textual spaces: Section 8 for in situ and Section 9 for ex situ conservation. Whereas in situ nature conservation is the ultimate goal of conservation, ex situ is limited in that it must be executed "predominantly for the purpose of complementing in-situ measures" (CBD, Article 9). As I discuss elsewhere (Braverman, 2014), although the U.S. Endangered Species Act of 1973 arguably the strongest conservation law in existence today-is not as explicit in its in situ/ex situ duality as the $\mathrm{CBD}$, its stated preference toward "historical range" and the disregard of its enforcers, the U.S. Fish and Wildlife, toward animal bodies in captive settings as measures of conservation recovery both rely on and reinforce the in situ/ex situ divide.

Such a hierarchical understanding of the relationship between in situ and ex situ conservation is not only the law "on the books," but also how many conservation biologists define and experience their work, as I have discovered in many of the interviews conducted for this project. Such a preferential treatment of situs is far from semantic; instead, it manifests in the everyday relationships between various conservation professionals and organizations around the world. One of the manifestations of the schism embedded in this terminology is the tense professional relationship between field conservationists, on the one hand, and conservationists who work in captive settings, mostly zoo professionals, on the other hand. One of my interviewees, a conservationist who works in both worlds, points out that: "Traditionally, zoos have been disliked by many of the field people because they don't like to see those animals in a 
captive setting and they don't necessarily feel like [zoos] are contributing all that much to their conservation" (Stoinski, interview). Another conservationist says, similarly, that, "there are still tensions between captive and wild communities, ... zoos versus field conservation" (Byers, interview).

Arguably, in situ and ex situ conservationists hold similar understandings of the term "nature." In situ is usually prioritized by both in situ and ex situ conservationists. This, based on their belief that the central object of conservation is a "first," pristine nature that exists outside of society. As mentioned, the very use of in situ and ex situ in the context of nature conservation assumes that there can, in fact, be a place that is "inside" nature, which can then be contrasted with a place that is "outside."

Yet more and more conservationists are questioning the essentialization of nature and exploring fresh approaches to biodiversity conservation that do not make recourse to the wilderness approach toward nature. Although still "sold" to the public as a more or less fixed entity that needs to be preserved or restored, such conservationists are beginning to overcome the traditional non-dynamic definition of nature. For example, Michael Rosenzweig explores the possibilities for reconciliation ecology in a "New Pangaea" (2003) that reorganizes the connections in which life has and will evolve. Along similar lines, nineteen ecologists have recently declared that, "it is time for conservationists to focus much more on the functions of species, and much less on where they originated" (Miller et al., 2011: 154). These scholars argue, further, that "[i]t is time for scientists, land managers and policy-makers to ditch this preoccupation with the native-alien dichotomy and embrace more dynamic and pragmatic approaches to the conservation and management of species - approaches better suited to our fastchanging planet" (ibid., 153; see also Hobbs et al., 2013). 
In the zoological world, William Conway criticizes the term "original habitat" (or "historic range" in the Endangered Species Act), which he suggests is a recurring term in the in situ/ex situ discourse. In his words,

[T] he whole business of in situ and ex situ are artificial concepts as we look into the future. Habitats are moving and changing, climate is changing. Animal populations in the past have been able to adapt to these changes, sometimes. [But] lots of time they couldn't and became extinct before humans came around. That's why we don't have giant sloths and mammoths. There used to be mammoths 11,000 years ago in the Bronx; 18,000 years ago there were polar bears in the South of France. That's not so long [ago]. So [the term] "original habitat" depends on how original you want to be. [W]e usually apply the same sort of meaning we do to history: "history" is since we were here, and "original" is the way it was when we remember it. But it doesn't necessarily mean it was here the day of the dinosaurs. So these terms have to be taken with great deal of flexibility (interview).

Nature and its implied originality are thus understood by Conway as relative and flexible concepts that depend on human definitions: "Original is the way it was when we remember it," he asserts. Conway's quote illuminates the failure of so many other conservation discourses to think adequately about temporal benchmarks, about the nonlinear or immanent nature of ecological complexes, and about the criteria by which to evaluate emergent or novel ecologies. Such considerations are part and parcel of the work of new ecologists, who argue the futility of appealing to a pure realm of nature as the touchstone of conservation practices. Instead, they argue that nature in the twenty first century will be a nature that we make (Botkin, 1990). "Future natures will be hybrid; their concern is the degree to which this moulding will be intentional or unintentional, desirable or undesirable (Lorimer 2008: 2048). Similarly, Nick Bingham and Steve Hinchliffe argue that the process of composing a common world necessitates a sense of natures as active outcomes rather than as pre-given starting points, as they are not "reducible to their conditions for they will go on to do more work in their own right" (2008: 85). Ultimately, for Bingham and Hinchliffe, it is because natures are "[n]either made-up nor pre- 
existing, both formed and forming, [...that they] mark the lures that mobilise an indeterminate world" (ibid.).

Despite these realizations, many conservationists, including Conway himself, are not prepared to give up wilderness. Here, in the words of Conway:

Why, for heavens sake, should we preserve fifteenth century Dutch paintings? Who cares? They don't make any difference to anybody. They are pretty to look at. Well, so are animals; [but they] are very much more than that. There was a time when we used to say "you have to preserve wildlife because of the importance it has in helping us to provide pure water and pure air" and so on and so forth, and of course some of that is true. But the biomass of human beings today is so big now and the biomass of wildlife is so small in comparison that that ecological argument is pretty hard to make. You are going to preserve them because you want to . . . because Dr. Braverman likes leopards or whatever it is that Dr. Braverman likes. You are going to preserve it because people have a sense of wanting to preserve something outside themselves. And that, ultimately, this is the most exciting, the most diverse, the most fascinating, the most beautiful expression of life: wild animals.

Prominent conservation biologist Michael Soulé states even more boldly than Conway: "If you see human beings as the major instrument in destroying most of biodiversity in the world, which they are, then it's easy to say that we're not part of nature. It's something like asking, was Adolf Hitler a human being? And it depends on your view of human beings." Here, the traditional romantic juxtaposition between nature and humans again raises its head.

\section{Naturalia and Artificilia: Early Zoos and Museum Collections}

Despite the strong preference toward in situ conservation, ex situ conservation has gained a foothold in seed and gene banks and, most prominently, in the work of modern zoos, which offer increasingly important ex situ conservation strategies. I have argued elsewhere that zoos are the quintessential manifestation of ex situ, the institution of nonhuman captivity (Braverman, 2014). Yet the history of zoos has not always been tied to notions of conservation. In fact, this is a fairly new phenomenon that began post-WWII, around the inception of the World Association of Zoos and Aquariums (WAZA) and alongside the establishment of the International Union for 
the Conservation of Nature (IUCN) (Penn et al., 2012). More pronounced links between zoos and conservation began in the 1970s and accelerated with the establishment of the European endangered species programs (EEPs) and the parallel Species Survival Plan (SSP) programs in North America in the 1980s (Braverman, 2012b). I will return to the ways in which ex situ conservation has been defined within the zoo institution later in this article.

Zoos have been around for centuries - and long before the emergence of the modern nature conservation movement. While the earliest recorded zoos date from the monastic kingdoms of Nebuchadnezzar of Babylon and Wen Wang of China (Braverman, 2012b: 26; Baratay and Hardouin-Fugier, 2004), in the seventeenth century what had once been menageries of exotica emerged alongside the museum as a scientific institution that focused on ordering nature. The history of zoos is thus deeply entangled with that of museums and other early natural history collections (Braverman, 2012b); the control of nature was the goal of early collecting practices and the driving force behind the ordering and cataloguing of artifacts and living things. Collectors of the sixteenth and seventeenth centuries devised strategies for the systematic categorization of the objects in their possession. In most cases, these objects were recorded and displayed in an organized manner, even if the criteria for organization were at times subjective. Regardless of their potential variations, the strategies adopted by these collectors enabled them to impose order on the natural world.

One of such collectors, John Tradescant, employed what David Berry calls "an organizational principle based on a classificatory system which differentiated between the wonders of nature, or naturalia, on the one hand, and the works of man, or artificialia, on the other" (Berry, 2011). This type of division was common in the period of the seventeenth century, with its collections of "curiosities." However, Tradescant's collection was unique in that "objects 
placed into the first category, that of naturalia, were further classified into subcategories consisting of the three primary orders of nature (animal, plant, and mineral), as then defined" (Berry, 2011). Objects placed into the category of artificialia were also placed into subcategories. As Berry notes, "within the encyclopedic context, all forms of data held equal weight when considered as parts of the whole of knowledge" (2011). Little priority was attached to one form of evidence over another, whether natural or artificial, real or imaginary.

In her excellent monograph Possessing Nature, history of science scholar Paula Findlen argues that collecting was a way of "maintaining some degree of control over the natural world and taking its measure" (1994: 4). These two activities, collecting and interrogating nature, met in the museum. "Possessing nature was part of a more widespread delight in collecting objects of scientific worth. ... Along with art, antiquities, and exotica, nature was deemed a desirable object to own" (Findlen, 1994: 2-3). Tactile as well as social, the philosophy of the museum "enhanced the Aristotelian definition of knowledge as a product of sensory engagement with nature" (Findlen, 1994: 5).

The strong ties between the evolution of zoos and that of natural history museums have already been studied, albeit briefly (Braverman, 2012b: 26-28). I argue more generally that these institutions share not only major goals and missions but also an administrative culture, which focuses on collections and exhibits and manages these collections through keepers, curators, and registrars. In menageries - the historical predecessors of modern zoological gardens-live animals replaced the dead naturalia of early museum displays. To keep their exhibited organisms alive, zoos had to come up with unique ways for managing live animals, including feeding and medical treatment. This extra attention by zoos to managing the life of their animal exhibits eventually necessitated the development of breeding plans and care manuals, which do not exist 
in most museum contexts. Nonetheless, the organizing themes remain strikingly similar in both zoos and museums: to manage what they both refer to as "collections" and "exhibits" through forms of classification. In the words of Judith Block, Registrar emeritus of the Smithsonian's National Zoo:

You can compare [living collections] to a museum collection in that a painting needs the right humidity, security, and protection from light, stuff like that. The same with a live animal; you have to make sure that it's ... safe and has the right temperature and humidity.... A wildebeest [is not] so unique that it's irreplaceable in the same way that a Rembrandt [painting] would be. This wildebeest is one of a species and has characteristics that will be useful for the population, but it's one of many [and thus] not so special (Block interview, ibid.: 125).

In the menageries, the wild and exotic animals - and until the early twentieth century, certain native humans as well (ibid.: 73-75) — were the sole focus of the exhibit. The design of the exhibit surrounding the animal included visibly human artifacts and, most prominently, bars and cages. The animal's domination by humans was visible; in fact, it was an important part of the menagerie exhibit. In the last five decades, however, zoos have redefined themselves as places that exhibit natural ecosystems, highlighting that they exist to save animal species and their habitats. The living animal thus becomes an important element in a larger and more sophisticated exhibit of nature. Immersion design has emerged around the world as the desired exhibit style: designed to immerse the zoogoer in what is envisioned as the original habitat of the displayed animal, immersion includes an array of sounds and sights from the perceived wild and an obscuration of human elements that might taint the view of the natural (ibid.: 33-38). It is already an important forging of situs in the ex situ, the out of site.

More than ever before, then, the existence of the modern zoo now depends on an ideal nature (Braverman, 2012a). In this age of conservation, the zoo's institutional existence depends on the animal's status as wild, exotic, and other (Braverman, 2012b: 30-49). This status is well exemplified through the narratives articulated in relation to the reappearance of Mercantour 
wolves in the French National Park of the Mercantour in 1992. According to Henry Buller, this event "was widely hailed as a reaffirmation, but also as a recasting, of the region's inherent biodiversity" (2008: 1589). The reappearance of these Mercantour wolves, Buller argues, marked for many "the achievement of some supreme preconstituted natural value-a celebration of the fact that here, at least, is an environment that can be "won back"” (ibid.). However, Buller problematizes such an appeal to a revitalized, ideal nature. Hinchliffe similarly points out that "[t]here is no timeless Nature, rendered as an eternal present or absent, to sit mutely outside an evolving society" (2007: 145).

Without such a wild, free, and timeless nature, the very notion of captivity is shattered. If every "situ" is but another form of captivity, for example, why would zoos exhibit the majesty of an exoticized nature? The perception of nature advanced by the zoo is one of an Edenic, untouched (by humans) and, most importantly, wild nature-the ultimate other of the zoo's captivity. Similarly, without the notion of captivity, pristine nature or wilderness as the very opposite of captivity cannot exist. The new institution of captivity has thus evolved hand-in-hand with the modern institution of wilderness and alongside ethics of conservation that effectively manage this fruitful schism. The wild animal at the zoo is no longer an object of naturalia by itself; rather, it requires the construction of an entire production of a nature "out there," and an existence of a body double in that nature-the zoo animal's duplicate in the wild for which it serves as ambassador - to be considered worth conserving by keeping in captivity. But the project of captivating animals engenders the transformation of animal bodies, as these translate into numerical calculations and genetic matter (Bear \& Eden, 2008; Lulka, 2004).

Put differently, the current definition of nature conservation depends on the bifurcation of in and ex situ. Here, from the IUCN: 
IUCN affirms that a goal of conservation is the maintenance of existing genetic diversity and viable populations of all taxa in the wild in order to maintain biological interactions, ecological processes and function. . . . The threats to biodiversity in situ continue to expand, and taxa have to survive in increasingly human-modified environments. ... The reality of the current situation is that it will not be possible to ensure the survival of an increasing number of threatened taxa without effectively using a diverse range of complementary conservation approaches and techniques including, for some taxa, increasing the role and practical use of ex situ techniques (IUCN, 2002; emphasis added).

The prioritization of wild nature, or in situ, over ex situ conservation is also apparent in texts produced by the World Association of Zoos and Aquariums, which defines conservation as "the securing of long-term populations of species in natural ecosystems and habitats wherever possible" (WAZA, 2005).

The in/ex situ paradigm also manifests in various definitions of conservation promoted by prominent global conservation organizations. For example, according to IUCN's Red List definitions, an animal that is extinct in situ (in the wild) is defined as "non-conserved," even if it still lives in captivity (IUCN, 2012a). In the words of Onnie Byers, CBSG Chair at the IUCN: "Real conservation is [defined as] self-sustaining populations in nature. If a species in total is only in captivity they call that 'not conserved.' The zoo community would prefer a more positive phrasing-[which] is something that I want to fight for at the World Conservation Congress" (interview). Similarly, U.S. Fish and Wildlife Service (USFWS) do not count captive animals when evaluating the endangered status of the species as part of their recovery plans. The USFWS Director tells me in an interview that "the Endangered Species Act is actually twofold. It is to conserve species that are endangered or threatened with extinction and the ecosystems on which they depend. So the context of the law is entirely oriented toward conserving species in the wild. We don't count species that are in captivity for recovery purposes" (Ashe, interview). Clearly, existing practices in conservation construct a preferential treatment of animals based on their placement "in" or "out" of nature, on a dyadic understanding of their biological situ. 


\section{The Birth of Zoos as Ex Situ Conservation Institutions}

In the 1970s, a system of legal codes came into effect that immensely limited the ability of zoos to take wild animals from the wild. In order to exist, zoos needed to find another way of producing animals. Fortunately, animals multiply and reproduce themselves. However, the task of orchestrating such reproductions from a genetic standpoint and the ethical dilemmas at stake has proven to be considerably more challenging than zoo professionals may have anticipated (Braverman, 2012b: 159-185).

Lisa Campbell and Matthew Godfrey study the ways in which genetic data supported the scaling-up of sea turtle conservation, thereby creating new "conservation territories." They show that "genetic data [was] used to argue that all hawksbills in the Caribbean were genetically related, and thus should be managed as a single, regional conservation territory" (2010: 900). Campbell and Godfrey conclude that "the science of genetics is implicated not only in delineating the physical space of conservation territories, but their governance structures." This discussion raises important ontological questions about what is a species-the basic unit of conservation biology—and which differences make a difference: genes, behavior, ecologies, etc. David Lulka's work (2004) on bison management in Yellowstone National Park provides another critical perspective on what he sees as the over usage of genetic management, which disconnects conservationists from the actual bodies of nonhuman animals, which are studied instead as population and species (Lulka, 2004: 446).

I have mentioned the legal changes that facilitated major alterations in the contemporary zoo. Yet the zoo's institutional shift to conservation was not only an imposition of outside legal norms. Increasingly, zoo personnel included many scientists who had just completed their PhDs in various in situ settings and who were passionate about conservation. These people looked for a 
way to become relevant to what they understood to be the most urgent challenges for conservation: the rapid disappearance of natural habitat and wildlife (Balmford et al., 1998). That, specifically, " 25 percent of all mammals, 12 percent of birds and more than a third of amphibians are threatened with extinction" (Dickie and Holst, 2007: 23). Western zoos have risen to the challenge, producing a complex conservation agenda that includes conservation education, captive breeding for the translocation of zoo animals in exchange with wildlife populations, participation and management of independent in situ projects, and sources of revenue for in situ projects. The next paragraphs will examine some of these conservation strategies, often referred to by zoo professionals and a growing group of conservationists as ex situ conservation.

\section{Ex Situ Conservation Strategies in Contemporary Zoos}

The WAZA Code of Ethics and Animal Welfare, adopted at the 58th Annual Conference of the World Association of Zoos and Aquariums (WAZA) in November 2003, includes the following principles:

- Assisting in achieving the conservation and survival of species must be the aim of all members of the profession.

...

- Promote the interests of wildlife conservation, biodiversity and animal welfare to colleagues and to society at large.

- Co-operate with the wider conservation community including wildlife agencies, conservation organisations and research institutions to assist in maintaining global biodiversity (WAZA, 2003).

In North America, the Association of Zoos and Aquariums current Five-Year Strategic Plan includes the following statements regarding conservation:

\section{Preamble}

Accredited zoos and aquariums are gateways through which millions of people learn about and value the rich diversity of life that is humankind's wildlife heritage. 


\section{Long Term Vision}

The Association of Zoos and Aquariums envisions a world where, as a result of the work of accredited zoos and aquariums, all people respect, value and conserve wildlife and wild places.

\section{Mission}

The Association of Zoos \& Aquariums (AZA) provides its members the services, high standards and best practices needed to be leaders and innovators in animal care, wildlife conservation and science, conservation education, the guest experience, and community engagement (AZA, 2010).

Contemporary zoos thus see themselves as a gateway through which wide audiences may be educated about the value of nature. For this education to take place, visitors must be able to intimately encounter the wonders of nature, which, it is believed, will convince them of the importance of its conservation. Such an intimate experience occurs through the visual display of wild animals, which are perceived as ambassadors for their conspecifics in the wild. "Unlike other international conservation NGOs, zoos have a physical site that can be visited. . . People don't tend to weep for the process of desertification but they are often inspired to act by the plight of charismatic species .... This common emotional response can be used to good effect for conservation purposes by zoo" (Dickie et al., 2007: 223, 229). According to the European Association of Zoos and Aquariums (EAZA), "EAZA empowers European citizens to learn about and contribute to global biodiversity conservation goals.

It is estimated that "more than 140 million people visit EAZA members each year, equivalent to approximately one in five European citizens" (EAZA, 2011: emphasis in original). On a global scale, an estimated one in ten of the world population visits a zoo each year, amounting to 600 million people worldwide (West and Dickie, 2007: 5). Western zoos see education as a central component of conservation; they believe that once the masses learn to care about the wild animals they encounter in zoos, they will also promote conservation of these 
animals in the wild. As much as the zoo presents itself as a representation-a simulacrum evenof nature, the institution of captivity is a simulacra of the wild (Bartram and Shobrook, 2000).

\section{Ex Situ Breeding}

Alongside their mission of conserving through education, zoos also see themselves as partaking in in situ conservation through ex situ, or captive, breeding. Again, because there can be no more taking from the wild, naturalia must be produced outside of nature. Detailed human calculations attempt to replace natural selection with complex genetic diversity configurations. Small animal population management in zoos has grown into a science that relies on sophisticated mathematical algorithms to map out and predict the future genetic diversity of captive populations (Ballou et al., 1995). Increasingly, this form of science-which attempts to imitate nature's diversity and to replace its various forms of selection-is being exported into in situ conservation projects for small animal populations (Lacy, interview). The IUCN's Conservation Breeding Specialist Group (CBSG) has come up with a One Plan approach to work around the problems of the in situ/ex situ divides. According to this organization's director, "The 'One Plan Approach' proposes integrated species conservation planning which considers all populations of the species both inside and outside their natural range under all conditions of management involving all responsible parties and engaging all available resources” (Byers, interview). Similarly, population biologists increasingly realize that, "No longer can the zoo world operate differently from a national park. The captive population are most likely not viable on their own ... and the wild population certainly is not viable on its own, either. We have to be working in partnership because we need each other" (Lacy, interview). Rather than seeing them as distinct populations, in situ and ex situ populations are now viewed as interconnected entities and commonly referred to as a "meta-population." 
In situ and ex situ conservation projects, certain conservationists have realized, affect each other in reciprocal ways. Under this realization, the Darwinian model of natural selection becomes the model for population management, which is in turn imposed on the process of reconstituting nature in the image of nature. An ongoing simulation process relies on the initial distinction between nature and science and asserts the scientific attempt to replicate nature, but then blurs the distinction between the two by weaving endless connections between various conservation sites.

Captive breeding is considered a strategy of ex situ conservation because of its potential to create a captive reserve population for endangered species or even for those species who are extirpated in the wild. These back-up supplies of animal bodies are referred to by conservationists as insurance (Soulé et al., 1986), or assurance (Dickie et al., 2007: 224), populations. According to many ex situ conservation narratives, once nature is eventually back on its feet, or once the population has strengthened itself, the vulnerable species can be reintroduced "back" into the wild. For example, conservationists argue in the context of amphibians that, "Maintenance of assurance populations in captivity may be the only route to survival for hundreds of species of amphibian, until a future point where chytrid is, if ever, eradicated from, or controlled in, the environment" (Dickie et al., 2007: 224). The value of captivity here again depends on the existence of a wild "out there." Reinforcing this prioritization of the wild, certain conservationists question whether humans should bother saving animals that can only exist in captivity (ibid., 229; but see Currie, interview).

Reintroductions of zoo animals into their wild habitats have been a source of pride for zoos and the pinnacle of their conservation efforts. Yet such reintroductions are quite rare for a variety of reasons, including the threat of "pollution" by disease transmission of natural 
populations and the risk of poaching (Braverman, 2012b: 182). Consequently, the IUCN enacts guidelines for reintroductions and other conservation translocations. The most recent guidelines, dated August 2012, map out a complex set of definitions and classifications. "Conservation translocation," is the overarching concept and is defined by the IUCN Guidelines as "the intentional movement and release of the focal species locally or globally, and/or restoring natural ecosystem functions or processes." Lastly, translocation is divided in the IUCN Guidelines into two categories: "population restoration" (translocation within indigenous range) and "conservation introduction" (translocation outside indigenous range). Each of these categories is finally divided into a variety of subcategories: reinforcement, reintroduction, assisted colonization, and ecological replacement (IUCN, 2012b). Important questions that should further be explored in this context are whether these guidelines in fact establish viable working definitions for the relationship between ex situ and in situ conservation and, if so, how they should be enforced.

\section{Captivity Outside Zoos}

The captivity of wild animals not only happens in zoos. More and more, ex situ breeding occurs on commercial farms, which are perceived by many conservationists as non- or even anticonservation. South Africa provides fascinating examples for the increasing blurring of lines between conservation and commercial breeding of wild animals. Peter Dollinger-previously the director of WAZA and currently the director of the Alpine Zoo Secretariat (a conglomerate of German and Swiss Zoos) — explains that there is "a huge trade in antelopes and giraffes and rhinos in South Africa. Farmers are breeding them, they are selling to other farmers and most of these animals are in fenced areas so you have to manage them." He further explains that, "A number of them have shifted to game farming and they do this partly ... for hunting tourism. So 
they make a living off of wildlife." Hamish Curriel, Director of South African nongovernmental organization Back to Africa, expands on the relationship between game reserves and conservation:

In a nutshell, I now have difficulty defining the word "conservation," because if I look at some game farms in South Africa ... I've got to say, "now, is that game farmer practicing conservation?" And what is conservation? Of course, the definition can get a bit blurred. . . . If it is activities that enhance the persistence of natural habitats and populations, then those guys are certainly doing that. [But] people in zoos, particularly, are very critical of this. They say it's bad, you know, that it's very bad to have a commercial value associated with animals. In Europe, you don't sell animals. You don't buy animals. You swap animals.

Such disparities between the various norms and practices relating to wild animals has

manifested in the following policy statement by the World Wildlife Fund (WWF):

In trying to determine strategies by which registered commercial ex situ breeding operations for Appendix I species could contribute to in situ conservation, additional difficulties are encountered in that many species have no identified in situ conservation programmes to which these operations could contribute. This fact in itself illustrates the concerns raised by the issue; i.e. commercial trade continues in Appendix I species with little or no attention focused on the in situ conservation of those species. ... For example - There are currently highly successful captive breeding programmes for Crocodylus siamensis (Siamese crocodile) in Thailand (16 registered with CITES), Vietnam (5 registered with CITES), and Cambodia (526 registered with the government, 6 registered with CITES). These operations breed and export tens of thousands of live crocodiles and products annually. ... At the same time, the species continues in drastic decline in all these range states, and is now virtually extinct in Thailand, where the last survey located only three animals remaining in the wild (WWF, 2004)

The statement that the animal is extinct in Thailand despite remaining alive in captive programs testifies to the alienation between in situ and ex situ accounts. If the animal is still alive, but not in its perceived natural or original location, should it be considered "conserved"? And what if the animal's habitat is highly dependent on human management, what would its conservation in that habitat mean then? These questions highlight that the ideas of "in" and "out" of nature are no longer useful and are in fact detrimental when devising a pragmatic and workable scheme for nature conservation in the Anthropocene. 


\section{Captivity in Nature}

Alongside the captivation of wild animals in zoos and commercial breeding farms, captivity also occurs in the "wild," or in situ. For example, Andrew Norton points out the many parallels between zoos and African safaris. In his words,

the nature on display is implicated in a hidden nexus of capital and power relations, including colonialism and capitalism; habitats and species populations are managed and animals become domesticated, through exposure to tourists rather than caging; and the experience is a constructed one which offers access to a "wild," primeval nature and attempts to hide its material and symbolic construction (1996: 369).

Similarly, Peter Dollinger of the Alpine Zoo Secretariat explains that:

In South Africa ... there is no single wild lion. [Kruger] is 600-square-km large. It is completely fenced. . . . But the problem is this 600 -square-km introduced a lot of animals into the area, thousands of antelopes and zebras and giraffes and rhinos and elephants and lions. The problem now is how to keep the lions under the pill, because otherwise the population would become too big. They have to implement birth control on the lions in this park. And that is the same in other parks too. Everywhere they have to cull. They used to cull in national parks some 300-400 elephants every year, for many, many years, to keep populations between 6 and 7000 animals (interview).

Because of the existence of fences and culling practices, Dollinger implies, there are no free lions in South Africa. "The idea of freedom," according to Dolinger, "is a human idea." "Animals have their needs and they must satisfy their needs and this can be done both in situ and in the zoo. So if a zoo enclosure provides all elements they need, that is okay for them." To illustrate his point, Dollinger recalls cases where animal liberations group had cut off the zoo's enclosure fences. "They expected the deer to go out—but they all stayed in. Of all the animals that they tried to liberate ... one wild cat got out and it just stayed 15-20 meters next to its enclosure" (interview). Zoo designer Monika Fiby also attempts a definition of human responsibility that does not depend on the naturalness of the habitat but on the degree of freedom afforded to nonhuman animals wherever humans are responsible for them. In her words, "Sometimes in the wild, animals have less and less choices.... [The difference between zoos 
and the wild] is the degree of our responsibility. How much are we responsible for their welfare? If we need to manage them then we are, to a certain degree, responsible" (interview).

Evidently, the relationship between captive and wild populations is increasingly complicated, illuminating the problems of bifurcated definitions such as wild/captive and in/ex situ. Specifically, the intense management of animal populations in nature reserves and other sites calls into serious question the ability to depict something as in situ or ex situ conservation in the first place. Certain conservationists have proposed, for example, the establishment of “extraction reserves" (Conway, 1998; Redford, 1998), which entail designating a natural habitat and managing it for enhancing zoo animal populations, including surveys of the habitat, the species present, ecological interactions, and the movement of animals in both directions-from the reserve to zoo populations and vice versa - to improve the genetic diversity of individual populations (Dickie, Bonner \& West, 2007: 228). Should such reserves be considered a site of nature or of captivity, of in situ or ex situ? If anything, this example demonstrates the growing array of gray sites, rather than the schematic black-and-white understanding so paradigmatic of traditional nature conservation ideologies.

Hamish Currie of Back to Africa explains some of the problems that have resulted from the rigid application of what he calls the "old school" definitions of in situ and ex situ. In his words,

There are very few places left that are actually really "wild." So whether you like it or not, you have to manage wildlife in an area the size of the Kruger National Park, which is hundreds of kilometers long. You have issues of disease that have to be managed, you have species in the Kruger Park that are diminishing very rapidly. So essentially, we talk "in situ," "ex situ" [but] that is, in fact, a very kind of old concept . . . . Because . . . in most scenarios you are managing animals. So it then boils down to the terminology . . it becomes a semantic issue. How are you defining what in situ is and what ex situ is? (interview). 
Currie also points to the disparity between the world of zoo scientists and academics and the realities of animal management in Africa. In his words,

Too many people — too many academics, too many people working in zoos—sort of think of these animals that they're keeping and they think well these are captive animals and then there's the wild. But they think of this vast continent of Africa where animals are running around, moving vast distances, all the genetic exchange is taking place, and that's the wild. What they don't realize is that it's now being sort of boiled down to smaller and smaller pockets and within those pockets animals might have to be managed (interview).

Currie's frustration with the zoos' impositions of strict conservation rules on issues of reintroduction and captive breeding in African countries of origin reveal the disparity between conservation in theory and conservation as practice. According to Steve Hinchliffe, "it should not be assumed that the facts of conservation, the real issues, pre-exist action and are thereby invariably polluted by human values, politics, cultures, ways of seeing and so on" (2008: 89). For Hinchliffe, when put into practice, facts are not always so clear. Accordingly, he argues, due to the very plenitude of nature conservation's objects, facts should be understood as "in process rather than clear cut issues" (ibid.). Hinchliffe, and with him much of the flourishing animal geography literature, highlight that conservation and natures are always made and constantly constructed.

Currie's frustration may also be interpreted as a critique of Europe's colonial approach toward conservation and nature. Although he does not engage such terms, Currie complains about Europeans that took African animals from their natural habitat and now refuse to return these animals for various reasons. This story sounds familiar: it has resurfaced recently in the context of museums, which face similar demands for returning "native cultural heritage" artifacts to their countries of origin (Cuno, 2008; Nafziger and Nicgorski, 2009). In the words of a NY Times reporter: "The news has become astonishingly routine: a major American museum announces it is relinquishing extraordinary antiquities because a foreign government claims they 
were looted and has threatened legal action or other sanctions if it doesn't get them back" (Eakin, 2013). This interchange connects back to the underlying commonalities between live and dead matter, between naturalia and artificilia, highlighting the fruitful parallels between museums and zoos and certain shared aspects of their conservation models.

\section{Conclusion}

This article has drawn on multiple interviews with conservationists to sketch out the genealogy of the terms in situ and ex situ, in general and in the context of nature conservation, demonstrating the immense power that they initially had, and that they still carry, in the discourse of prominent conservationists. Prompted by the ecological challenges that face today's world (referred to by some as the Anthropocene), certain conservationists are, however, starting to question the validity of such "old school" schisms of nature versus human, wild (or free) versus captive (or non-free) animals, and in situ and ex situ conservation. This article has explored and advocated the erosion of such schisms, mainly in the context of conservation practices by zoos but also in the context of game reserves and parks.

Finally, the article has depicted current efforts by conservationists to bridge the in/ex situ divide, for example through the "One Plan" approach promoted by IUCN's CBSG. Parallel efforts to bridge between in and ex situ conservation are now mushrooming throughout the conservation world, for example in re-wilding projects (Lorimer, 2013), Brownfield wildlife (Lorimer, 2008), reconciliation ecologies (Rosenzweig, 2003), and the "land sharing" versus "land sparing" debates in Europe (e.g. Green et al., 2005). Such attempts are intrinsically linked to this project in that they all question traditional conservation ideologies and dualistic understandings of nature-culture. Implicitly or explicitly, they also all raise the same question: what counts (and what should count) as nature conservation? Jamie Lorimer's work on urban 
living roof projects (2008) provides such an example. Although they are neither wild nor pretty in the traditional "English countryside" sense, Lorimer argues that living roofs are an innovative urban conservation strategy where wildlife habitat is created on top of new and old buildings in the city. At the same time, Lorimer depicts the incredible tensions that urban conservationists must overcome before their work is recognized as conservation, which I would argue are the result of the historical bifurcation that I have delineated here between "in" and "out" of nature.

Drawing on the work of relational geographers and others, I have similarly set out to challenge the binary forms of identity applied to nature, this time in their translation into the fundamental understanding of conservation as performed either in or ex situ, and the interrelated perception that such spaces cannot overlap. Such a bifurcated understanding of nature relies on what actor network theorists have called "regional topologies"-namely, "a version of the social in which space is exclusive. Neat divisions, no overlap" (Mol and Law, 1994). Indeed, the terms in situ and ex situ are intimately linked to historical conceptions of space and place. Given the investment in this spatial ordering for the past century, putting an end to the in situ/ex situ divide will also necessarily impact our conceptions of the place of wildlife, the place of conservation, and the spatial relationships between the two. The end of the in situ/ex situ divide must therefore be accompanied by a careful outline of alternative, nonlinear, and relational conceptions of space and place-effectively, a new conservation paradigm. Such a paradigm must recognize the fluidity and hybridity of bodies and spaces and their constant becomings. As Lorimer suggests, "Future natures will be hybrid; their concern is the degree to which this moulding will be intentional or unintentional, desirable or undesirable" (Lorimer, 2008: 2048).

Conservation practices are in fact increasingly going down this very path. More and more conservationists are recognizing the various movements and exchanges of animal bodies in 
between regional spaces, the dynamic creation and dissolution of "in between" spaces and hybrid bodies, and the messy overlap of natures that consist of complex human-nonhuman networks and assemblages in various stages of becoming. These various depictions and practices illuminate a possible alternative to nature: an abandonment of "in" and "out" that has so characterized traditional conservation narratives, in favor of an understanding of conservation that focuses on the situ — the site itself: matter, flesh, body; life, death and other forms of being, perhapswithout the emotional and ideological messiness that occurs whenever nature (again, nature with a capital "N") enters the picture.

My proposal, I should clarify, is not merely to replace the bifurcation between nature and captivity with a continuum between the two (although this is probably a first step in the right direction), but is far more radical: it is to acknowledge that for nature to exist, humans and nonhumans will have to reinvent it and, moreover, that the level of "naturalness" of a site-its historical originality, if you will—becomes almost irrelevant, misleading even, when considering possible strategies for conservation. The extant habitats of a growing number of species are becoming less viable for their survival for a variety of reasons, including global warming, disease, drought, and deforestation. To maintain many species, an alternative habitat (or the existing one) must be constructed and managed.

Indeed, captive settings increasingly provide more viable habitats than a species' historic setting, and are often used interchangeably with the former habitat, such as in the case of the Rio Grande silvery minnow, whose eggs are scooped up in spoons (64,000 eggs were saved this way in summer 2013), hatched in captive facilities (because the river dries up in the increasingly arid summers), and then, in the irrigation period, translocated in SUVs to upstream ponds to avoid extinction (Braverman, draft). For endangered species, such stories are becoming more the rule 
than the exception. The handful of animals that remain from a species on the brink of extinction must often be translocated into intensely managed sites to survive (see, e.g., in the case of the Tasmanian devil, certain bats, many amphibians). A new, livable and real nature must thus be negotiated for the conservation of life (for example, Maria Island in the case of the Tasmanian devil, an aquarium in the case of the Pahrump pool fish, and so forth, Braverman, draft).

If we erase the term "Nature" from our conservation discussions, the rationale for distinguishing in situ from ex situ conservation, in their current definition at least, would likely cease to exist. With no nature "out there" versus a human world "in here," the meaning of and the criteria for conservation will need to find less stable and more nuanced and dynamic grounds that depend on interspecies networks and relations and necessitate a democratic discussion of what it is that is important to conserve.

\section{Acknowledgment}

I would like to thank Jamie Lorimer, John Schlegel, this journal's anonymous reviewers, and editor Harvey Neo for insisting with me on a few important questions raised in this article. I am also grateful to my research assistants Eleanor Gold, Ajitpaul Mangat, and Adam Dunstan for their invaluable research. The research for this article was assisted by the American Council of Learned Societies' Charles A. Ryskamp Research Fellowship and by the Baldy Center for Law \& Social Policy.

\section{List of Interviews}

George Abungu, Former Director General, National Museums of Kenya \& cultural heritage professional - Interview Date: 2/13/13

Dan Ashe, Director, U.S. Fish and Wildlife Service - Interview Date 7/17/13

Judith Block, Registrar Emeritus, Smithsonian Institution, National Zoological Park, Washington, DC - Interview Date: 9/4/09

Evan Blumer, Former Director, The Wilds, CBSG board member - Interview Date: 2/18/13

Onnie Byers, Chair, Conservation Breeding Specialist Group (CBSG) - Interview Date: 8/1/12

William Conway, Former Director, Bronx Zoo - Interview Date: 28/1/13

Hamish Currie, Director, Back to Africa - Interview Date: 1/10/13

Peter Dollinger, Director of Alpine Zoo Secretariat, Zoo Office Bern - Interview Date: 1/9/13

Monika Fiby, Zoo designer \& Director, Zoolex - Interview Dates: 9/24/12 and 11/20/12 
Kenneth Hamma, Executive Director for Technology Strategy, Getty Museum \& Cultural heritage consultant - Interview Date: 2/5/13

Robert Lacy, Population biologist, Chicago Zoological Society (Brookfield Zoo) - Interview Date: $7 / 31 / 12$

Michael Soulé, Conservation biologist - Interview Date: 2/6/13

Tara Stoinski, Manager of Conservation Partnerships/McGrath Chair of Conservation and Science, Zoo Atlanta - Interview date: 1/7/13

\section{References}

Agamben G (1998) Homo Sacer: Sovereign Power and Bare Life. Stanford: Stanford University Press.

Anderson G (2004) Reinventing the Museum: Historical and Contemporary Perspectives on the Paradigm Shift. Lanham, MD: AltaMira Press.

Anderson K (1995) "Culture and nature at the Adelaide Zoo: at the frontiers of human geography." Transactions, Institute of British Geographers NS 20, 275-294.

Association of Zoos and Aquariums (2010) Association of Zoos and Aquariums 5-Year Strategic Plan, adopted at the 2010 AZA Annual Conference, Houston TX, 12-16 September 2010. Available at http://www.aza.org/StrategicPlan/ (accessed 28 January 2013).

Ballou JD, Gilpin M and Foose TJ (1995) Population Management for Survival \& Recovery: Analytical Methods and Strategies in Small Population Conservation. New York: Columbia UP.

Balmford A, Mace GM and Ginsberg JR (1998) Conservation in a Changing World. Cambridge: CUP.

Baratay E and Hardouin-Fugier E (2004) Zoo: A History of Zoological Gardens in the West. London: Reaktion Books.

Barrow MV (2009) Nature's Ghosts: Confronting Extinction from the Age of Jefferson to the Age of Ecology. Chicago: University of Chicago Press.

Bartram R and Shobrook S (2000) "Endless/End-Less Natures: Environmental Futures at the Fin de Millennium." Annals of the Association of American Geographers 90: 370-380.

Bear C and Eden S (2008) "Making space for fish." Social and Cultural Geography 9.5: 487504.

Berry D (2011) Tradescant Collection. In: Ashmolean Museum of Art and Archaeology, University of Oxford. Available at:

www.ashmolean.org/ash/amulets/tradescant/tradescant04.html (accessed 28 January 2013). 
Biernacki, P, and Waldorf D (1981) "Snowball Sampling: Problems and Techniques of Chain Referral Sampling." Sociological Methods and Research 10.2, 141-163.

Bingham N and Hinchliffe S (2008) "Reconstituting natures: Articulating other modes of living together." Geoforum 39.1, 83-87.

Botkin D (1990) Discordant Harmonies: A New Ecology for the Twenty-first Century. Oxford: OUP.

Bramwell A (1989) Ecology in the 20 $0^{\text {th }}$ Century: A History. New Haven: YUP.

Braun B (2006) Towards a new earth and a new humanity: Nature, ontology, politics. In Castree N and Gregory D (eds) David Harvey: A Critical Reader. Oxford: Blackwell, 191-222.

Braverman I (2012a) Zootopia: Utopia and Dystopia in Zoological Garden. In: Giesecke A and Jacobs N (eds) Earth Perfect? Nature, Utopia, and the Garden. London: Black Dog Publishing.

Braverman I (2012b) Zooland: The Institution of Captivity. Stanford: SUP.

Braverman I. Wild Life: The Nature of In Situ and Ex Situ Conservation, 2014, under review.

Braverman I, Blomley N, Delaney D and Kedar A (2014) The Expanding Spaces of Law: A Timely Legal Geography. Stanford: SUP. Introduction available online: http://papers.ssrn.com/sol3/papers.cfm?abstract_id=2235164

Buller H (2008) "Safe from the wolf: biosecurity, biodiversity, and competing philosophies of nature." Environment and Planning A 40, 1583-1597.

Burney DA and Burney LP (2010) “Inter situ conservation: Opening a 'third front' in the battle to save rare Hawaiian plants." BGjournal 6 (1): 16-19.

Campbell L M and Godfrey M H (2010) "Geo-political genetics: Claiming the commons through species mapping.” Geoforum 41.6, 897-907.

Conway W (2003) The Role of Zoos in the $21^{\text {st }}$ Century. International Zoo Yearbook 38(1): 7 13.

Cronon W (1996) Uncommon Ground: Rethinking the Human Place in Nature. New York: W. W. Norton \& Co.

Crosby, AW (1986) Ecological Imperialism. Cambridge: CUP.

Cuno, J (2008) Who Owns Antiquity: Museums and the Battle Over Our Ancient Heritage. Princeton and Oxford: PUP.

Davis M et al. (2011) Don't judge species on their origins. Nature 474: 153-4. 
Dickie LA, Bonner JP and West C (2007) In situ and ex situ conservation: blurring the boundaries between zoos and the wild. In: Zimmermann A, Hatchwell M and Dickie LA et al. (eds) Zoos in the $21^{\text {st }}$ Century: Catalysts for Conservation? Cambridge: CUP, pp. 220-235.

Dickie LA and Holst B (2007) How do national and international regulations and policies influence the role of zoos and aquariums in conservation? In: Zimmermann A, Hatchwell $\mathrm{M}$ and Dickie LA et al. (eds) Zoos in the $21^{\text {st }}$ Century: Catalysts for Conservation?, Cambridge: CUP, pp. 22-35.

Donahue J and Trump D (2006) The Politics of Zoos: Exotic Animals and their Protectors. Northern Illinois University Press.

Eakin H “The Great Giveback.” The NY Times, January 26, 2013.

European Association of Zoos and Aquaria (2011) About EAZA. Available at http:/www.eaza.net/about/Pages/Introduction.aspx (accessed 28 January 2013).

Fleishman E et al. (2011) Top 40 Priorities for Science to Inform US. Conservation and Management Policy. Bioscience 61, 290-300.

Green RE (2005) Farming and the Fate of Wild Nature. Science 307: 550-555.

Guerrant EO, Havens K and Maunder M, et al. (2004) Ex Situ Plant Conservation: Supporting Species in the Wild. Washington, DC: Island Press, 2004.

Haraway D (1991) Simians, Cyborgs, and Women: The Reinvention of Nature. New York: Routledge.

Haraway D (2003) A Companion Species Manifesto: Dogs, People, and Significant Otherness. Chicago: Prickly Paradigm.

Haraway D (2008) When Species Meet. Minneapolis: University of Minnesota.

Hediger H (1964) Wild Animals in Captivity. New York: Dover Publications.

Heise UK (2008) Sense of Place and Sense of Planet: The Environmental Imagination of the Global. Oxford: OUP.

Hinchliffe S (2007) Geographies of Nature. London: Sage.

Hinchliffe S (2008) "Reconstituting nature conservation: Towards a careful political ecology." Geoforum 39.1, 88-97.

Hobbs RJ et al. (2013) Novel Ecosystems: Intervening in the New Ecological World Order. Wiley-Blackwell. 
IUCN (2002) IUCN Technical Guidelines on the Management of Ex Situ Populations for Conservation. Approved at the $14^{\text {th }}$ Meeting of the Programme Committee of Council, Gland Switzerland, 10 December 2002.

IUCN (2012a) The IUCN Red List of Threatened Species. Version 2012.2. Available at www.iucnredlist.org (accessed 21 January 2013).

IUCN (2012b) IUCN Guidelines for Reintroductions and Other Conservation Translocations. Adopted by SSC Steering Committee at Meeting SC46, 5 September 2012. Available at http://www.issg.org/pdf/publications/Translocation-Guidelines-2012.pdf (accessed 28 January 2013).

Kingsland SE (1995) Modeling Nature: Episodes in the History of Population Ecology. Chicago: CUP.

Kirksey SE and Helmreich S (2010) “The Emergence of Multispecies Ethnography.” Cultural Anthropology 25.4, 545-576.

Kohn E (2007) How Dogs Dream: Amazonian Natures and the Politics of Transspecies Engagement. American Ethnologist 34.1, 3-24.

Lacy RC (2010) Re-thinking ex situ vs. in situ Species Conservation. In: Proceedings of 65 ${ }^{\text {th }}$ WAZA Annual Conference (ed G Dick), Cologne, Germany, 18-19 October 2010: pp. 2529.

Lacy RC (2012) Achieving True Sustainability of Zoo Populations. Zoo Biology. Epub ahead of print 2 July 2012. DOI: 10.1002/zoo.21029.

Latour B (2011) From multiculturalism to multinaturalism: What roles of method for the new socio-scientific experiments? Nature and Culture 6: 1-17.

Latour B (2010) An attempt at a 'compositionist manifesto'. New Literary History 41: 471-490.

Latour B (2004) Politics of Nature: How to Bring the Sciences into Democracy. Cambridge MA: HUP.

Latour B (1993). We Have Never Been Modern. Cambridge, MA: HUP.

Lorimer J (2006) “What about the nematodes.” Social and Cultural Geography 7.4: 539-558.

Lorimer, J (2007) “Nonhuman Charisma. Environment and Planning D 25: 911-932.

Lorimer, J (2008) Living Roofs and Brownfield Wildlife. Environment and Planning A. 40: 2042-2060.

Lorimer J (2012) Multinatural geographies for the Anthropocene. Progress in Human Geography 36.5: 593-612. 
Lorimer J (2013) Wild experiments at the Oostvaardersplassen: rethinking environmentalism in the Anthropocene (draft) (cited with permission).

Lulka D (2004) "Stabilizing the herd: fixing the identity of nonhumans." Environment and Planning D 22: 439-463.

Marris M (2011) Rambunctious Garden: Saving Nature in a Post-Wild World. New York: Bloomsury.

Merchant C (1980) The Death of Nature: Women, Ecology, and the Scientific Revolution. San Francisco: Harper \& Row.

Mitman G (1992) The State of Nature: Ecology, Community, and American Social Thought, 1900-1950. Chicago: UCP.

Mol A and Law J (1994) "Regions, networks and fluids: Anaemia and social topology." Social Studies of Science 24: 641-671.

Morton T (2007) Ecology Without Nature. Cambridge MA: HUP.

Nafziger JAR and Nicgorski AM (2009) Cultural Heritage Issues: The Legacy of Conquest, Colonization, and Commerce. Danvers MA: Martinus Nijhoff Publishers

Norton A (1996) "Experiencing nature: The reproduction of environmental discourse through safari tourism in East Africa." Geoforum 27(3): 355-373.

Penn L, Gusset M and Dick G (2012) 77 Years: The History and Evolution of the World Association of Zoos and Aquariums 1935-2012. WAZA.

Redford KH, Brandon K and Sanderson SE (1998) Parks in Peril: People, Politics, and Protected Areas. Washington, DC: Island Press.

Redford KH, Amato G and Baillie J, et al. (2011) What Does it Mean to Successfully Conserve a (Vertebrate) Species. BioScience 61(1): 39-48.

Rose DB and van Dooren T, ed (2011) Unloved Others: Death of the Disregarded in the Time of Extinctions. Australian Humanities Review (special issue) 50.

Rosenzweig ML (2003) Win-Win Ecology: How the Earth's Species Can Survive in the Midst of Human Enterprise. Oxford: Oxford University Press.

Scarascia-Mugnozza GT and Perrino P (2002) The History of ex situ Conservation and Use of Plant Genetic Resources. In: Engels JMM, Ramantha Rao V, Brown AHD et al. (eds) Managing Plant Genetic Diversity. Oxford: CABI Publishing, pp. 1-22.

Sellars, RW (1997) Preserving Nature in the National Parks: A History. New Haven: YUP.

Slater C (1996) Amazonia as Edenic Narrative. In: Cronon W (ed) Uncommon Ground: Rethinking the Human Place in Nature. New York: W.W. Norton \& Co., pp. 114-131. 
Smith N (1984) Uneven Development: Nature, Capital, and the Production of Space. New York: Blackwell.

Soulé M, Conway W, Foose T and Gilpin M (1986) The Millenium Ark: How Long a Voyage, How Many Staterooms, How Many Passengers? Zoo Biology 5: 101-113.

Szerszynski B (2012) The End of the End of Nature: The Anthropocene and the Fate of the Human. Oxford Literary Review 34: 165-184.

United Nations (1992a) Article 8: In-situ Conservation. Convention on Biological Diversity, Rio de Janeiro, Brazil, 5 June 1992, pp. 6-7. United Nations Treaty Collection. Available at http://treaties.un.org/Pages/CTCTreaties.aspx?id=27\&subid=A\&lang=en (accessed 27 January 2013).

United Nations (1992b) Article 9: Ex-situ Conservation. Convention on Biological Diversity, Rio de Janeiro, Brazil, 5 June 1992, p. 7. United Nations Treaty Collection. Available at http://treaties.un.org/Pages/CTCTreaties.aspx?id=27\&subid=A\&lang=en (accessed 27 January 2013).

Warren, CR (2009) Using the native/alien classification for description not prescription: a response to Christopher Preston. Progress in Human Geography 33(5): 711-713.

Whatmore, S (2002) Hybrid Geographies: Natures, Cultures, Spaces. London: Sage.

Wikipedia. "In Situ." Available at http://en.wikipedia.org/wiki/In_situ (last viewed Feb. 19, 2013).

West $\mathrm{C}$ and Dickie LA (2007) Introduction: is there a conservation role for zoos in a natural world under fire? In: Zimmermann A, Hatchwell M and Dickie LA et al. (eds) Zoos in the $21^{\text {st }}$ Century: Catalysts for Conservation? Cambridge: CUP, pp. 3-11.

World Association of Zoos and Aquariums (WAZA) (2003) WAZA Code of Ethics and Animal Welfare, adopted at the $58^{\text {th }}$ Annual Conference of the World Association of Zoos and Aquariums, San José Costa Rica, 19 November 2003. Available at http://www.waza.org/en/site/conservation/code-of-ethics-and-animal-welfare (accessed 28 January 2013).

World Association of Zoos and Aquariums (WAZA) (2005) Building a Future for Wildlife: The World Zoo and Aquarium Conservation Strategy. Berne, Switzerland: WAZA Executive Office.

World Wildlife Foundation (WWF) (2004) WWF Position Statement, $13^{\text {th }}$ Meeting of the Conference of the Parties to CITES, Bangkok Thailand, 2-14 October 2004. Available at assets.panda.org/downloads/ecop13insituexsitupositionpaper.pdf (accessed 28 January 2013). 